\title{
The Risk Assessment Method based on Multi-Attribute Fuzzy Decision-Making in the Application of the Internal Control
}

\author{
Jiamin Fang \\ Branch of Accounting, Jilin Business and Technology College, Changchun \\ 130062, PR China \\ ccfjm@sina.com
}

\begin{abstract}
Under the background of global economic integration, with international competition between enterprises increasing, the risks are more diverse. Financial crisis has led to many companies became the victim of the financial crisis era. Chinese enterprises want to survive and develop healthy in the fierce competition, they must enhance the competitiveness of enterprises, improve themselves from the inside, strengthen enterprise management, establish the perfect internal control system, find a suitable internal control and risk management system for our enterprises, identify and measure enterprise in the face of internal and external risks in order to improve competition ability of enterprise, realize the value of the enterprise has become the current most urgent task of enterprise. So enterprises need to establish the risk assessment system to ensure that enterprises find risk timely, and take corresponding measures. This paper establishes the network marketing performance evaluation index system followed the principles of "scientific, objective, systematic, feasibility and stability". Then use interval-valued intuitionistic fuzzy sets generalized mixed weighted aggregation operator to calculate the evaluation value. The reason of this paper use interval-valued intuitionistic fuzzy sets is some index value is not necessarily a certain number in real life, the interval-valued intuitionistic fuzzy sets can describe some parameter values in greater detail; The generalized mixed weighted aggregation operator is used to calculate the risk evaluation value of various enterprises, then compare the evaluation value and put forward the corresponding strategy. Finally, enumerating instances to validate the method adopted by this paper used in the enterprise risk evaluation is feasible and effective.
\end{abstract}

Keywords: enterprise risk; interval-valued intuitionistic fuzzy set; generalized mixed weighted aggregation operator; multi-attribute decision-making

\section{Introduction}

Enterprise internal control is carried out by the board of directors, the board of supervisors, managers and staff together, to achieve the process of control objectives. And internal control also has some problems, such as the recognition of enterprise internal control exist a deviation, corporate governance structure exist defect, lack of strong internal control execution, etc., then one of the ways to perfect the internal control is to strengthen the control of risk assessment. Risk assessment refers to the enterprise shall timely recognition and analysis risk related to realize the goal of internal control of operational activities of the system, and determine the corresponding strategies reasonably. Each enterprise will produce different degrees of risk in the process of operation, some of risks have not great influence on enterprise operation, but there are some risks pose a threat to the survival of enterprise, therefore, for the healthy and stable development of the enterprise, the risk assessment is very important. In recent years, our country enterprises often have risk that unable to response timely 
and effective and cause bigger loss. Our country enterprises can make risk assessment well, and they can deal with risks better, risk management work can carry out better. Risk assessment is getting more and more attention from enterprise managers and academic researchers. Therefore, establishing a set of risk assessment index system in line with the current economic environment and their conditions, and using the relevant evaluation model method to measure, are of great significance.

In 1949, in the report that the internal control: a coordinated system elements and the importance of the management authorities and the independence of certified public accountants, the American institute of certified public accountants audit program committee made an authoritative definition of internal control for the first time. After the 50s, market competition is intensifying, make internal control expand to the enterprise internal each domain, the content is increasingly rich. In October 1985, the commission released the audit program announcement no. 29 restates definition of internal control. It is divided into accounting control and management control for the first time [1]. After the $80 \mathrm{~s}$, the focus of research is deepened from the general meaning to specific content gradually [2]. At present, most researchers in China put focus on the general theory of internal control, the second they put focus on the relationship research between internal controls, or between internal control and corporate governance, in view of the internal control risk assessment study is few.

In this paper, risk assessment that the author studies also belongs to the risk management, refer to the related theory of risk management. Since the 1940s, with the rapid development of science and technology economy, the scale of enterprises is increasing, its problems and relationship they faced grew more complex. As a result, more and more companies begin to attach importance to risk management, enterprise risk management become one of the three major activities of the company (strategic management, operation management, and risk management)[3]. COSO (The Committee of Sponsoring Organizations of The Tread way Commission)(2004) points out that the enterprise risk management is a process that is designed to identify potential matters may affect the main body, management risk to make it within the risk capacity of the main body, and provide reasonable assurance for achieving the goals[4]. Li Xianglu (2004) study the various contents of modern enterprise risk management by applying financial engineering theory, she thinks that financial engineering can play a role in the modern enterprise risk management, mainly displays in: (1) the credit risk management and control;(2) price risk management and control;(3) the number risk management and control;(4) agent risk management and control;(5) merger risk management and control. Thus she thinks that people can broaden the thinking of the people in the risk management by means of financial engineering effective risk management, reduce the cost of risk management, and improve the efficiency of risk management [5]. Ni Yanling (2004) argues that companies risk refers to actual earnings of enterprise are short of expected earnings due to the uncertainty of internal and external environment of the enterprise, the complexity of the production and operation activities, and limited ability of companies, the root cause leading to companies in trouble and failure is improper enterprise internal management and poor management [6]. Zhang Zhenchuan (2004) studies the risk of the enterprise from the perspective of value management, namely based on VBM value management idea, the enterprise risk system and the influence of its contribution to the enterprise value are discussed, and then sums up some mechanism of the value of enterprise risk and try to establish enterprise risk management cycle system and management system beginning in strategic decision-making, through process control, finally performance evaluation and responsibility allocation [7]. Tang Zhenda (2005) summed up the enterprise risk as " the uncertainty of events that may affect the implementation of modern enterprise strategic target happen", at the same time pointed out that contact the modern enterprise risk management and strategic management, 
implement three transformation, namely the management mode changes from the traditional crisis response to risk optimum combination, management means change from static risk management to dynamic risk management, risk management style changes from micro risk management into macro management, eventually improve the level of enterprise risk management, promote enterprise value [8]. Zhou Xian (2005) studied the main risks in the process of modern enterprise operation, he divide the specific objectives of risk management into the target before loss and the target after loss. Put forward three principles of risk management: considering the size of the potential losses, considering the relationship between the profit and loss, considering the opportunity of the loss. He also explored how to set up the mechanism of enterprise risk management in modern times [9]. Shi Yuying(2005) summarizes qualitative and quantitative theory, technology and method in the process of modern risk management, this paper introduces the new direction of the enterprise Risk Management, namely IRM (Integrated Risk Management), integrate the enterprise risk management, strategy Management and Management can help each other, improve management efficiency, reduce management costs. At the same time, the development of information technology provides the necessary platform for the specific implementation and operation of integrated management mode, promotes the transformation from theory to practice [10]. Mi Xinying (2005) etc, studied the key points of implementation of effective enterprise risk management, namely: (1) set up the consciousness of risk management; (2) master and use of risk control methods properly. At the same time, discuss problems should be paid attention at the three stages of the implementation of risk management: identify risk and assess, crisis happen, after crisis [11]. Chen Xiaohong etc. (2006) studied the relationship between modern enterprise risk management and auditing management, and pointed out that the enterprise risk management cannot leave the internal control system and risk control evaluation, looking for defects, put forward suggestions of improvement, improve management audit that based on the economic benefit, efficiency and effect of business activities. Management audit has an important role in establishing and improving the enterprise risk management mechanism, improving the enterprise ability to cope with risks, increasing the enterprise value, realizing the goal of enterprise [12]. Guo Jikun thought that enterprise risk management step into a new stage, at the same time, he studied the systematism of risk management objectives, namely according to the enterprise overall strategic target, develop a total risk management goal, layer upon layer decompose and refine the goal in accordance with the organizational structure and enterprise business process, forming a tree target management system, and manage all kinds of comprehensive risk of all enterprises[13].The Economist Intelligence Unit (1998) [14] pointed out that top managers carry out a complete business risk assessment as reduce the risk of every level effectively, enterprises think that must assess and control business risk persistently, revalue, and update again, so can ensure that risk reduce to the level that organization overall risk management strategy required. Risk assessment process include: firstly, identify risks, the process must know the risk identified is controllable or uncontrollable, help the implementation of this process by risk code; Secondly, look for the origin of the risk; Thirdly, measure risk, determine the impact of the significant risks and the possible risks. Malone and Matt (2005) [15] suggested that carry out the safety risk assessment to ensure the control of information technology. Expose internal and external weaknesses of the enterprise by the risk assessment process, to make incorrect control and plotting exposure. Credit risk expert Altman (1968) [16] take the lead in applying multivariate discriminant analysis method to financial crisis, the enterprise bankruptcy and default risk analysis, the technology minimize the differences within the group, at the same time maximize differences between groups by analyzing a group of variables. He pointed out that in 2003 [17], the basis of comprehensive analysis of credit loans and bonds portfolio is making the initial evaluation of each asset analysis in the portfolio based on the independence. Helmut Elsinger and Alfed Lehar (2003) [18] introduced that analyze and 
assess the banking system by using the VAR model, only that unite all aspects, evaluating the whole system of bank effectively. Both in 2005 [19] use the market information in risk assessment of the banking system, determine the stability of the banking system to determine important risk rely on market data, simulate the internal bank market through the network, then simulate some serious plot to pressure on the banking system to check bug. Deloitte [20] believe that the key risk assessment activities generally include risk identification conference, interview, risk questionnaire and simple risk worksheet. Activity is determined by the needs and culture of each enterprise, it has been proven that the method of risk assessment shall combine the enterprise framework with practical experience of risk assessment. This will ensure that successful implementation of risk assessment in identification and divide risk levels. Liu Guojing, Zhang Lei (2004) [21] pointed out that the method system of commercial bank credit project risk assessment based on the risk matrix has the characteristics of strong program, the combination of quantitative and qualitative, simple and feasible. Risk assessment method system includes designing risk matrix, ranking risk importance, the determination of the level of overall risk and expected default probability. Its risk assessment includes risk identification, risk quantitative analysis, making risk response plan and the determination of conclusion of risk evaluation. Cui Yi (2005) [22] put forward methods of enterprise risk identification. For pure risk, analyze form by using of risk management designed by the insurance industry, related risk and insurance management science; Design questionnaire specific to the existence and effectiveness of enterprise internal control point, including financial and non-financial internal control point. For speculative risk, design form based on the characteristics of the enterprise, and economic risk factors can begin from the table above, analyze risk factors that affect the sales revenue of the enterprise in the macro and industry environment; Then analyze how cost structure and financial structure of enterprise affect the fluctuation range of sales incomes of the enterprise, and form enterprise total payment risk, whether the matching between them. Gao Jianming, Yang Jianan (2001) [23] points out that the technology risk assessment refers to assess the probability, time of occurrence, the condition of continuous of risk, risk consequences, risk degree. In order to deal with multi-index evaluation, he combines fuzzy evaluation and analytic hierarchy process, eventually he establishes a complete system, including qualitative indicators adopt the combination of expert investigation and fuzzy statistics method, and quantitative analysis index uses the fuzzy mathematics method. Fu Shaochuan (2005) [24] points out that the e-commerce evaluation steps include determine the scope, risk identifies, risk assessment, risk analysis results. The paper also introduces the comprehensive risk analysis method, firstly, group brainstorming panel, and then combine and classify ideas come up, make assessment by experts Delphi experts group that composed of network experts, finally, repeated use of the Delphi method to predict the future state of enterprises.

Throughout the research of predecessors, almost no one use interval-valued intuitionistic fuzzy sets generalized mixed weighted aggregation operator to evaluate enterprise risk. This paper synthesizes research methods at home and abroad, first of all, builds enterprise risk index evaluation system by following the "scientific, objective, systematic, feasibility and stability" principles, then uses interval-valued intuitionistic fuzzy sets generalized mixed weighted aggregation operator to evaluate risk of enterprise.

\section{Establish Enterprise Risk Evaluation Index System}

To evaluate enterprise risk, firstly, build the evaluation index system of enterprise risk, the choice of evaluation index directly affects the effect of the enterprise risk assessment. The choice of evaluation index must follow the principle of "scientific, purposeful, systematic, feasibility, stability". This paper makes ample consideration of the financial risk, human resources risk, market risk, credit risk. Financial risk 
main include the critical income from operation, interest bearing debt ratio, degree of financial leverage; Human resource risk main include two aspects of turnover rate and staff compensation satisfaction; Market risk main include the market share, product life cycle and market competition degree; Credit risk main include the service complaint rate and enterprise overdue loan repayment rate.

Table 1. Enterprise Risk Evaluation Index System

\begin{tabular}{|c|c|c|c|}
\hline \multirow{11}{*}{$\begin{array}{c}\text { enterprise risk } \\
\text { evaluation } \\
\text { index system }\end{array}$} & First class & \multicolumn{2}{|c|}{ Second class indicator } \\
\hline & \multirow{3}{*}{ Financial risk } & $\begin{array}{l}\text { Critical income } \\
\text { from operation }\end{array}$ & $x_{1}$ \\
\hline & & $\begin{array}{l}\text { Interest bearing } \\
\text { debt ratio }\end{array}$ & $x_{2}$ \\
\hline & & $\begin{array}{l}\text { Degree of financial } \\
\text { leverage }\end{array}$ & $x_{3}$ \\
\hline & \multirow{2}{*}{$\begin{array}{c}\text { Human resource } \\
\text { risk }\end{array}$} & Turnover rate & $x_{4}$ \\
\hline & & $\begin{array}{c}\text { Staff compensation } \\
\text { satisfaction }\end{array}$ & $x_{5}$ \\
\hline & \multirow{3}{*}{ Market risk } & Market share & $x_{6}$ \\
\hline & & Product life cycle & $x_{7}$ \\
\hline & & $\begin{array}{c}\text { Market competition } \\
\text { degree }\end{array}$ & $x_{8}$ \\
\hline & \multirow{2}{*}{ Reputation risk } & $\begin{array}{l}\text { Service complaint } \\
\text { rate }\end{array}$ & $x_{9}$ \\
\hline & & $\begin{array}{l}\text { Enterprise overdue } \\
\text { loan repayment rate }\end{array}$ & $x_{10}$ \\
\hline
\end{tabular}

$x_{1}$ : Critical income from operation=interest/ (1-ratio of sales to cost-sales tax rate);

$x_{2}$ : Interest bearing debt ratio $=($ short-term borrowing + long-term loan + bonds payable + interest payable)/total indebtedness;

$x_{3}$ : Degree of financial leverage=earnings before interest and tax/ (earnings before interest and tax-interest);

$x_{4}$ : Turnover rate is the percentage of the total number of employees to separated employees within the statistical period. Turnover rate $=$ number of staff wastage/ (beginning number of staff + number of staff increased current period)*100\%;

$x_{5}$ : Staff compensation satisfaction, refers to the psychological state that employees compare the enterprise economic compensation and non-economic compensation for their expectations. It can be stated with excellent, good, bad, generally there is a uniform rule 
of the relationship between language variables and interval-valued intuitionistic fuzzy sets;

$x_{6}$ : Market share $=$ leading product sales/market sales of the same kind of products;

$x_{7}$ : Product life cycle, for short PLC, is the market life of the product, that is, the whole process of a new product from beginning to enter the market to being eliminated by the market, the cycle is long, medium and short, in this paper, excellent, good, bad replace them;

$x_{8}$ : The market competition degree refers to the market status that the product is, and has the advantage and disadvantage. It can be stated with excellent, good, bad, generally there is a uniform rule of the relationship between language variables and interval-valued intuitionistic fuzzy sets;

$x_{9}$ : Service complaint rate $=$ number of customer complaint $/$ number of service;

$x_{10}$ : Enterprise overdue loan repayment rate $=$ Enterprise overdue loan repayment frequentness/ current number of loans;

\section{Table 2. The Relationship between Language Variables and Interval-Valued} Intuitionistic Fuzzy Sets

\begin{tabular}{|c|c|}
\hline Language variables & Interval-valued intuitionistic fuzzy sets \\
\hline Excellent, & $<[0.7,0.8],[0.1,0.2]>$ \\
\hline Good & $<[0.4,0.5],[0.2,0.3]>$ \\
\hline Bad & $<[0.1,0.2],[0.5,0.6]>$ \\
\hline
\end{tabular}

\section{Interval-Valued Intuitionistic Fuzzy Sets}

Definition 1: Set $X$ is a non-empty classic set, triples that on $X$ like $A=\left\{<\mathrm{x}, \mu_{A}(\mathrm{x}), v_{A}(\mathrm{x})>\mid \mathrm{x} \in \mathrm{X}\right\}$ is called intuitionistic fuzzy sets on $X$. Including $\mu_{A}$ : $X \rightarrow[0,1]$ and $v_{A}: X \rightarrow[0,1]$ are the membership function of $X$, and $0 \leq \mu_{A}(\mathrm{x})+v_{A}(\mathrm{x}) \leq 1$, here $\mu_{A}(\mathrm{x}), v_{A}(\mathrm{x})$ is the membership degree and non-membership degree about $x$ of $X$ belong to $A$ respectively, expressed as the evidence that support element $x$ belong to $A$ export lower bound of affirmative membership degree and the evidence that oppose element $x$ belong to $A$ export lower bound of negative membership degree. For example $\left[\mu_{A}(\mathrm{x}), v_{A}(\mathrm{x})\right]=[0.5,0.3]$, In voting model which can be interpreted as in 10 people, 5 people agree, three people oppose and two people default.

For random intuitionistic fuzzy sets $A$ on $X, \pi_{A}(\mathrm{x})=1-\mu_{A}(\mathrm{x})-v_{A}(\mathrm{x})$ is called intuitionistic index of element $x$ in intuitionistic fuzzy sets $A$. Intuitionistic index of element $x$ in intuitionistic fuzzy sets $A$ expresses hesitation that $x$ belong to $A$. Obviously, $0 \leq \pi_{A}(\mathrm{x}) \leq 1, \quad x \in X$.If $\pi_{A}(\mathrm{x})=0$, intuitionistic fuzzy sets $A$ becomes fuzzy sets. Thus, intuitionistic fuzzy sets is a generalization of the fuzzy sets, fuzzy sets is special case of intuitionistic fuzzy sets.

Definition 2: $D[0,1]$ is the set of all closed subinterval on interval $[0,1], X$ is a non-empty classic set, triples that on $X$ like $A=\left\{\left\langle\mathrm{x}, \mu_{A}(\mathrm{x}), v_{A}(\mathrm{x})\right\rangle \mid \mathrm{x} \in \mathrm{X}\right\}$ is called interval-valued intuitionistic fuzzy sets on $X$, including $\mu_{A}: X \rightarrow[0,1]$ and $v_{A}: X \rightarrow[0,1]$ are membership function on $X, 0 \leq \sup \mu_{A}(\mathrm{x})+\sup v_{A}(\mathrm{x}) \leq 1 。$ Here interval $\mu_{A}(\mathrm{x}), v_{A}(\mathrm{x})$ is the membership degree and non-membership degree about $x$ of $X$ belong to $A$ respectively. For each $x \in X, \mu_{A}(\mathrm{x})$ and $v_{A}(\mathrm{x})$ are closed interval on [0,1], its lower bound, upper bound are $\left[\mu_{A}(\mathrm{x})\right]^{L},\left[\mu_{A}(\mathrm{x})\right]^{U}$ and $\left[v_{A}(\mathrm{x})\right]^{L},\left[v_{A}(\mathrm{x})\right]^{U}$ respectively. All interval-valued intuitionistic fuzzy sets on $X$ are recorded as IVIFS $[X]$. 
For each interval-valued intuitionistic fuzzy set on $X$, following functions express the uncertainty of $x$ belong to interval-valued intuitionistic fuzzy set $A$, namely, hesitancy: $\pi_{A, \text { inf }}(\mathrm{x})=1-\sup _{x} \mu_{A}(\mathrm{x})-\sup _{x} v_{A}(\mathrm{x}), \quad \pi_{A, \text { sup }}(\mathrm{x})=1-\inf _{x} \mu_{A}(\mathrm{x})-\inf _{x} v_{A}(\mathrm{x})$.

Obviously, $\pi_{A}: X \rightarrow D[0,1]$. The lower bound and upper bound of $\pi_{A}(\mathrm{x}) \operatorname{are}\left[\pi_{A}(\mathrm{x})\right]^{L}$ and $\left[\pi_{A}(\mathrm{x})\right]^{U}$, and $\left[\pi_{A}(\mathrm{x})\right]^{L}=1-\sup _{x} \mu_{A}(\mathrm{x})-\sup _{x} v_{A}(\mathrm{x})$, and $\left[\pi_{A}(\mathrm{x})\right]^{U}=1-\inf _{x} \mu_{A}(\mathrm{x})-\inf _{x} v_{A}(\mathrm{x})$. $\left(\left[\pi_{A}(\mathrm{x})\right]^{L},\left[\pi_{A}(\mathrm{x})\right]^{U}\right) \in \mathrm{D}[0,1]$, in essence, interval-valued intuitionistic fuzzy set is the generalization of the intuitionistic fuzzy sets, the interval-valued intuitionistic fuzzy set is the expansion and extension of normal fuzzy sets.

Definition $3 \quad X$ is a non-empty classic set, $A, B \in I V I F S[\mathrm{X}], \lambda>0$ is any real number,

$$
\left.A=\left\{<\mathrm{x},\left[\left[\mu_{A}(\mathrm{x})\right]^{L},\left[\mu_{A}(\mathrm{x})\right]^{U}\right],\left[\left[v_{A}(\mathrm{x})\right]^{L},\left[v_{A}(\mathrm{x})\right]^{U}\right]\right\}>\mid \mathrm{x} \in \mathrm{X}\right\}
$$

$\left.B=\left\{<\mathrm{x},\left[\left[\mu_{B}(\mathrm{x})\right]^{L},\left[\mu_{B}(\mathrm{x})\right]^{U}\right],\left[\left[v_{B}(\mathrm{x})\right]^{L},\left[v_{B}(\mathrm{x})\right]^{U}\right]\right\}>\mid \mathrm{x} \in \mathrm{X}\right\}$, operational relationship is stipulated as follow:

(1) The sum of interval-valued intuitionistic fuzzy sets:

$$
\begin{aligned}
& A+B=\left\{<x,\left[\left[\mu_{A}(\mathrm{x})\right]^{L}+\left[\mu_{B}(\mathrm{x})\right]^{L}-\left[\mu_{A}(\mathrm{x})\right]^{L}\left[\mu_{B}(\mathrm{x})\right]^{L},\left[\mu_{A}(\mathrm{x})\right]^{U}+\left[\mu_{B}(\mathrm{x})\right]^{U}-\left[\mu_{A}(\mathrm{x})\right]^{U}\left[\mu_{B}(\mathrm{x})\right]^{U}\right],\right. \\
& \left.\left[\left[v_{A}(\mathrm{x})\right]^{L}\left[v_{B}(\mathrm{x})\right]^{L},\left[v_{A}(\mathrm{x})\right]^{U}\left[v_{B}(\mathrm{x})\right]^{U}\right]>\mid x \in X\right\}
\end{aligned}
$$

(2) The product of interval-valued intuitionistic fuzzy sets:

$$
\begin{aligned}
& A B=\left\{<x,\left[\left[\mu_{A}(\mathrm{x})\right]^{L}\left[\mu_{B}(\mathrm{x})\right]^{L},\left[\mu_{A}(\mathrm{x})\right]^{U}\left[\mu_{B}(\mathrm{x})\right]^{U}\right],\left[\left[v_{A}(\mathrm{x})\right]^{L}+\left[v_{B}(\mathrm{x})\right]^{L}-\left[v_{A}(\mathrm{x})\right]^{L}\left[v_{B}(\mathrm{x})\right]^{L},\right.\right. \\
& \left.\left.\left[v_{A}(\mathrm{x})\right]^{U}+\left[v_{B}(\mathrm{x})\right]^{U}-\left[v_{A}(\mathrm{x})\right]^{U}\left[v_{B}(\mathrm{x})\right]^{U}\right]>\mid x \in X\right\}
\end{aligned}
$$

(3) The product of interval-valued intuitionistic fuzzy sets and number:

$\lambda A=\left\{<x,\left[1-\left(1-\left[\mu_{A}(\mathrm{x})\right]^{L}\right)^{\lambda}, 1-\left(1-\left[\mu_{A}(\mathrm{x})\right]^{U}\right)^{\lambda}\right],\left[\left(\left[v_{A}(\mathrm{x})\right]^{L}\right)^{\lambda},\left(\left[v_{A}(\mathrm{x})\right]^{U}\right)^{\lambda}\right]>\mid\right.$

$x \in X\}$

(4) The power of interval-valued intuitionistic fuzzy sets:

$A^{\lambda}=\left\{<x,\left[\left(\left[\mu_{A}(\mathrm{x})\right]^{L}\right)^{\lambda},\left(\left[\mu_{A}(\mathrm{x})\right]^{U}\right)^{\lambda}\right],\left[1-\left(1-\left[v_{A}(\mathrm{x})\right]^{L}\right)^{\lambda}, 1-\left(1-\left[v_{A}(\mathrm{x})\right]^{U}\right)^{\lambda}\right]>\mid\right.$

$x \in X\}$

When interval-valued intuitionistic fuzzy set $\left.A=\left\{<\mathrm{x},\left[\left[\mu_{A}(\mathrm{x})\right]^{L},\left[\mu_{A}(\mathrm{x})\right]^{U}\right],\left[\left[v_{A}(\mathrm{x})\right]^{L},\left[v_{A}(\mathrm{x})\right]^{U}\right]\right\}>\mid \mathrm{x} \in \mathrm{X}\right\}$ has just one element, the shorthand for $\left.A=<\left[\mu_{A}^{L}, \mu_{A}^{U}\right],\left[v_{A}^{L}, v_{A}^{U}\right]\right\}>$. The collection of single element interval-valued intuitionistic fuzzy sets is shorthand for $F_{1}$.

To comparing and sorting interval-valued intuitionistic fuzzy sets, define score value and precision of interval-valued intuitionistic fuzzy sets $\left.A=<\left[\mu_{A}^{L}, \mu_{A}^{U}\right],\left[v_{A}^{L}, v_{A}^{U}\right]\right\}>$ are respectively:

$$
\left\{\begin{array}{l}
M(\mathrm{~A})=\frac{\mu_{A}^{L}+\mu_{A}^{U}-v_{A}^{L}-v_{A}^{U}}{2} \\
\Delta(\mathrm{A})=\frac{\mu_{A}^{L}+\mu_{A}^{U}+v_{A}^{L}+v_{A}^{U}}{2}
\end{array}\right.
$$

Obviously, $M(\mathrm{~A}) \in[-1,1], \Delta(\mathrm{A}) \in[0,1]$. Hence, for interval-valued intuitionistic fuzzy sets $A_{i}$ and $A_{j}$, its relations or sorting as follows:

(1) If $M\left(A_{i}\right)>M\left(A_{j}\right), A_{i}$ is greater than $A_{j}$, denoted by $A_{i}>A_{j}$.

(2) If $M\left(A_{i}\right)=M\left(A_{j}\right)$,

(2a) If $\Delta\left(A_{i}\right)=\Delta\left(A_{j}\right), A_{i}$ is equal to $A_{j}$, denoted by $A_{i}=A_{j}$;

(2b) If $\Delta\left(A_{i}\right)<\Delta\left(A_{j}\right), A_{i}$ is less than $A_{j}$, denoted by $A_{i}<A_{j}$;

(2c) If $\Delta\left(A_{i}\right)>\Delta\left(A_{j}\right), A_{i}$ is greater than $A_{j}$, denoted by $A_{i}>A_{j}$. 


\section{Model based on Interval-Valued Intuitionistic Fuzzy Sets Generalized Mixed Weighted Aggregation Operator}

Assume that $\left.A_{j}=<\left[\mu_{j}^{L}, \mu_{j}^{U}\right],\left[v_{j}^{L}, v_{j}^{U}\right]\right\}>(j=1,2, \ldots, n)$ is interval-valued intuitionistic fuzzy sets. If map $g_{\omega, w}: F_{1}^{n} \rightarrow F_{1}$ satisfied

$g_{\omega, w}\left(A_{1}, A_{2}, \ldots, A_{n}\right)=\sqrt[q]{\sum_{k=1}^{n} w_{k} B_{k}^{q}}$

$g$ is called interval-valued intuitionistic fuzzy sets generalized mixed weighted aggregation operator.

In formula(2): $w=\left(w_{1}, w_{2}, \ldots, w_{n}\right)^{\mathrm{T}}$ is the weight vector (or position weight vector) that is associated with the mapping $g ; \omega=\left(\omega_{1}, \omega_{2}, \cdots, \omega_{\mathrm{n}}\right)^{\mathrm{T}}$ is the weight vector of interval-valued intuitionistic fuzzy sets $A_{\mathrm{j}}(j=1,2, \cdots, n) ; B_{k}(k=1,2, \cdots, n)$ is the $k$ largest element of $n$ interval-valued intuitionistic fuzzy sets $A_{j}(j=1,2, \ldots, n)$ according to certain ordering method, $A_{j}(j=1,2, \cdots, n)$ is interval-valued intuitionistic fuzzy sets by $A_{j} \quad(j=1,2, \cdots, n)$ weighting $n \omega_{j}$, namely $A_{j}=n \omega_{j} A_{j} ; q>0$ is control parameter.

Assume that $\left.A_{j}=<\left[\mu_{j}^{L}, \mu_{j}^{U}\right],\left[v_{j}^{L}, v_{j}^{U}\right]\right\}>(j=1,2, \ldots, n)$ is interval-valued intuitionistic fuzzy sets, $\quad B_{k}=<\left[\mu_{k}^{L}, \mu_{k}^{U}\right],\left[\hat{v}_{k}^{L}, v_{k}^{U}\right]>(k=1,2, \cdots, n)$ is the $k$ largest element of $n$ interval-valued intuitionistic fuzzy sets $A_{j}=n \omega_{j} A_{j} \quad(j=1,2, \ldots, n)$ according to certain ordering method, the result computed by interval-valued intuitionistic fuzzy sets generalized mixed weighted aggregation operator, namely formula (2) is still interval-valued intuitionistic fuzzy sets, and

$$
\begin{aligned}
g_{\omega, w}\left(A_{1}, A_{2}, \cdots, A_{n}\right)= & {\left[\sqrt[q]{1-\prod_{k=1}^{n}\left[1-\left(\mu_{k}^{L}\right)^{q}\right]^{w_{k}}}, \sqrt[q]{1-\prod_{k=1}^{n}\left[1-\left(\mu_{k}^{U}\right)^{q}\right]^{w_{k}}}\right], } \\
& {\left[1-\sqrt[q]{1-\prod_{k=1}^{n}\left[1-\left(1-\hat{v}_{k}^{L}\right)^{q}\right]^{w_{k}}},\right.} \\
& \left.1-\sqrt[q]{1-\prod_{k=1}^{n}\left[1-\left(1-\hat{v}_{k}^{U}\right)^{q}\right]^{w_{k}}}\right]>
\end{aligned}
$$

Weight problems are involved with operators above, determination of weight in solving multiple objective (attribute) decision problem is critical, after many experts and scholars studying over the years, there are many kinds of method of determining the weight. Mainly divide into three categories: subjective weighting method (such as analytic hierarchy process), objective weighting method (such as principal component analysis), subjective and objective comprehensive integration weighting method (such as the comprehensive integration weighting method based on the sum of squares of deviations).

Subjective weighting method and objective weighting method have their own strengths, but have some disadvantages, so this paper uses the subjective and objective comprehensive integration weighting method, synthesizing advantages of subjective weighting method and objective weighting method, namely, weighting the weight get by the subjective weighting method and objective weighting method.

When make evaluation by using interval-valued intuitionistic fuzzy sets generalized mixed weighted aggregation operator, the steps as follow:

(1) Construct interval-valued intuitionistic fuzzy sets matrix

Scheme set is denoted by $A=\left\{A_{1}, A_{2}, \ldots, A_{m}\right\}$, attribute set is denoted by $X=\left\{x_{1}, x_{2}, \ldots, x_{n}\right\}, \quad$ the evaluation of scheme $A_{i} \in A$ about quantitative attribute $x_{j} \in X$ 
is interval-valued intuitionistic fuzzy sets. Construct interval-valued intuitionistic fuzzy sets matrix as follows:

$$
A=\left[\begin{array}{cccc}
A_{11} & A_{12} & \cdots & A_{1 m} \\
A_{21} & A_{22} & \cdots & A_{2 m} \\
\cdots & \cdots & \cdots & \cdots \\
A_{n 1} & A_{n 2} & \cdots & A_{n m}
\end{array}\right]
$$

(1) Calculate ${ }^{A_{j}}$

Calculate $^{A_{j}}$ by using $A_{j}=n \omega_{j} A_{j}$.

(2) Order each index interval-valued intuitionistic fuzzy sets $A_{j}$

Calculate the score value and the accurate value of interval-valued intuitionistic fuzzy set $A_{j}$ by using formula (1), and order each interval-valued intuitionistic fuzzy set according to order method below formula(1).

(3) Calculate evaluation value of all schemes

Substitute sorted interval-valued intuitionistic fuzzy sets $B_{k}=<\left[\mu_{k}^{L}, \mu_{k}^{U}\right],\left[\hat{v}_{k}^{L}, \hat{v}_{k}^{U}\right]>$ $(k=1,2, \cdots, n)$ and each target position weight $w=\left(w_{1}, w_{2}, \ldots, w_{n}\right)^{\mathrm{T}}$ into formula (3), and calculate evaluation value of each scheme.

(4) Compare each scheme

Calculate the score value and the accurate value of each scheme, and carry on the sorting.

\section{Empirical Analysis}

Now evaluate risk of four marketing enterprises $A_{1}, A_{2}, A_{3}, A_{4}$ of China, the index data of companies are known, these data are in the form of interval-valued intuitionistic fuzzy sets, calculate the weight by using subjective and objective comprehensive weighting method, and evaluate risk of each enterprise by using interval-valued intuitionistic fuzzy sets generalized mixed weighted aggregation operator, make the enterprise to understand their and competitor's risk situation, and make corresponding analysis, so that put forward the corresponding strategy.

We give index values of four companies as follow:

Table 3. Index Values of Four Companies

\begin{tabular}{|c|c|c|}
\hline index & $A_{1}$ & $A_{2}$ \\
\hline$x_{1}$ & $<[0.1,0.2],[0.5,0.6]>$ & $<[0.2,0.3],[0.5,0.6]>$ \\
\hline$x_{2}$ & $<[0.2,0.4],[0.3,0.5]>$ & $<[0.1,0.2],[0.4,0.7]>$ \\
\hline$x_{3}$ & $<[0.1,0.3],[0.4,0.5]>$ & $<[0.1,0.3],[0.4,0.6]>$ \\
\hline$x_{4}$ & $<[0.4,0.5],[0.3,0.4]>$ & $<[0.1,0.3],[0.3,0.5]>$ \\
\hline$x_{5}$ & $<[0.4,0.5],[0.2,0.3]>$ & $<[0.1,0.2],[0.5,0.6]>$ \\
\hline$x_{6}$ & $<[0.4,0.6],[0.2,0.3]>$ & $<[0.2,0.3],[0.2,0.4]>$ \\
\hline
\end{tabular}




\begin{tabular}{|c|c|c|}
\hline$x_{7}$ & $<[0.7,0.8],[0.1,0.2]>$ & $<[0.1,0.2],[0.5,0.6]>$ \\
\hline$x_{8}$ & $<[0.1,0.2],[0.5,0.6]>$ & $<[0.4,0.5],[0.2,0.3]>$ \\
\hline$x_{9}$ & $<[0.3,0.4],[0.1,0.2]>$ & $<[0.2,0.3],[0.4,0.6]>$ \\
\hline$x_{10}$ & $<[0.4,0.5],[0.1,0.2]>$ & $<[0.3,0.4],[0.4,0.6]>$ \\
\hline index & $A_{3}$ & $A_{4}$ \\
\hline$x_{1}$ & $<[0.3,0.5],[0.4,0.5]>$ & $<[0.1,0.3],[0.4,0.6]>$ \\
\hline$x_{2}$ & $<[0.2,0.3],[0.4,0.6]>$ & $<[0.5,0.6],[0.1,0.3]>$ \\
\hline$x_{3}$ & $<[0.7,0.8],[0.1,0.2]>$ & $<[0.1,0.2],[0.6,0.7]>$ \\
\hline$x_{4}$ & $<[0.1,0.2],[0.4,0.6]>$ & $<[0.1,0.2],[0.4,0.5]>$ \\
\hline$x_{5}$ & $<[0.7,0.8],[0.1,0.2]>$ & $<[0.4,0.5],[0.2,0.3]>$ \\
\hline$x_{6}$ & $<[0.1,0.3],[0.4,0.6]>$ & $<[0.4,0.5],[0.2,0.3]>$ \\
\hline$x_{7}$ & $<[0.4,0.5],[0.2,0.3]>$ & $<[0.4,0.5],[0.2,0.3]>$ \\
\hline$x_{8}$ & $<[0.7,0.8],[0.1,0.2]>$ & $<[0.1,0.2],[0.5,0.6]>$ \\
\hline$x_{9}$ & $<[0.3,0.4],[0.4,0.6]>$ & $<[0.1,0.3],[0.4,0.6]>$ \\
\hline$x_{10}$ & $<[0.4,0.5],[0.2,0.3]>$ & $<[0.1,0.2],[0.4,0.5]>$ \\
\hline
\end{tabular}

Determine the index weight by using subjective and objective comprehensive integration weighting method, and calculated weight of the index is $w=(0.04,0.1,0.26,0.08,0.16,0.02,0.06,0.1,0.05,0.13)^{\mathrm{T}}$.

According to the interval-valued intuitionistic fuzzy sets is given in Table 3 and formula (1), calculated the score values of each index are: $M_{11}=-0.4, M_{12}-0.3, M_{13}=-0.25$, $M_{14}=0.1, M_{15}=0.2, M_{16}=0.25, M_{17}=0.6, M_{18}=-0.4, M_{19}=0.2, M_{110}=0.3$. Obviously, $M_{17}>M_{110}>M_{16}>M_{15}=M_{19}>M_{14}>M_{13}>M_{12}>M_{11}=M_{18}$.

Therefore, use formula(3) to calculate the evaluation value of $A_{1}$ is $\left.r_{1}=<\left[\mu_{1}^{L}, \mu_{1}^{U}\right],\left[v_{1}^{L}, v_{1}^{U}\right]\right\}>, \quad$ similarly, also calculate the evaluation value of $A_{i}(i=2,3,4)$ as follow: 
Table 4. Evaluation Value, Score Value and Accurate Value of Scheme

\begin{tabular}{|c|c|c|}
\hline & $r_{i}$ & $M\left(A_{i}\right)$ \\
\hline$A_{1}$ & $<[0.2348,0.3636],[0.3856,0.4696]>$ & -0.1284 \\
\hline$A_{2}$ & $<[0.0013,0.4139],[0.2730,0.4587]>$ & -0.15825 \\
\hline$A_{3}$ & $<[0.3023,0.4673],[0.3260,0.4566]>$ & -0.0065 \\
\hline$A_{4}$ & $<[0.0000,0.2445],[0.3966,0.6555]>$ & -0.4038 \\
\hline
\end{tabular}

The above-mentioned score values generate a bar chart as shown:

M

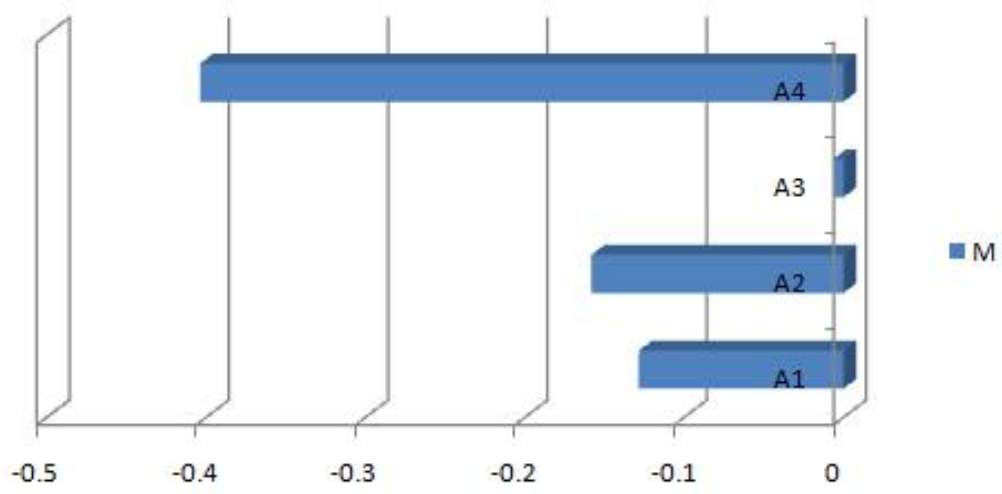

Figure 2. Bar Chart of Evaluation Results

The figure above shows that $M\left(A_{3}\right)>M\left(A_{1}\right)>M\left(A_{2}\right)>M\left(A_{4}\right)$, but the size of assessment worth happens to be contrary to enterprise risk, so the sorting of risk of these companies is $A_{4}, A_{2}, A_{1}, A_{3}$. Compare four companies, from the intuitive judgment, the risk of enterprise $A_{4}$ is indeed the highest, and the risk of enterprise is indeed lowest. Therefore, the experimental result is consistent with the artificial judgment, and the model is used for enterprise risk evaluation is feasible. The risk of enterprise $A_{4}$ is highest due to the low critical income from operation, the low market competition degree, and the high Interest bearing debt ratio. The risk of enterprise $A_{3}$ is lowest due to the high degree of financial leverage, the high staff compensation satisfaction, the high market competition degree and the low turnover rate. So according to the evaluation results and combining with the parameter values, each enterprise can come up with the corresponding strategies, to reduce the risk of the enterprise.

\section{Conclusion}

Under the environment of global economic integration, the competition is more and more fierce, the risk enterprises faced is more and more diversified, the enterprise must establish a good internal control system, strengthen the assessment and control of risk. So, it is necessary to assess the risk of enterprises in real time. This paper has made the following results on the risk evaluation: (1) This paper constructs the enterprise e-marketing performance evaluation system by following the principles of "scientific, objective, systematic, feasibility and stability"; (2) This paper represents index values of each scheme with interval-valued intuitionistic fuzzy sets. Because interval-valued 
intuitionistic fuzzy sets use interval number to represent the degree of membership, the degree of non-membership and hesitation of intuitionistic fuzzy sets, so it can be more flexible to express uncertain information. (3) Use interval-valued intuitionistic fuzzy sets generalized mixed weighted aggregation operator to evaluate the risk of enterprise objectively and effectively. (4) Finally, use of empirical analysis to verify the model and the method used by the enterprise risk evaluation is feasible and effective. Of course, there will be other methods are also suitable for this field, that still can continue to study.

\section{References}

[1] N M.Koziol, "Heritage of Management Accounting Control". Management Accounting, April, (1996), pp. 23-30

[2] Treadway Committee. Report of the National Commission On Fraudulent. Financial Reporting,(1987),pp. 89-103.

[3] J R Willianms, "Risk Management and Insurance[M]", New York Irwin / McGraw,(1998).

[4] F Hongxing, W Hongyi, "Enterprise risk management-integrated framework", Northeast university of finance and economics press,(2005).

[5] L Xianglu. "Apply financial engineering to construct modern enterprise risk management system [J]". Financial Theory and Practice, no. 10, (2004), pp. 27-29.

[6] N Yanling, L Haiyin, Y Xiang. "Comparison of SC risk control with enterprise risk control [J]". Logistics Technology, no. 12, (2004), pp. 40-42.

[7] Z Zhenchuan. "Discussion of modern enterprise risk value management issues [J]". Accounting Research, no. 3, (2004), pp. 55-58.

[8] T\Zhenda, K\ Xuening. "The research of modern enterprise risk management [J]". Academic Forum, no. 1, (2006), pp. 129-135.

[9] Z Xian. "Thinking about modern enterprise risk management mechanism [J]". Market Weekly Economics, no. 10, pp. 18- 19.

[10] S Yuying, Q Lin, L Liang, H Dan. "Sketch of modern enterprise risk management methods [J]". Science-technology and Management, no. 4, (2005), pp. 88-90.

[11] M Xinying, L Shenghua. "Analyze "key point" of implementation of modern enterprise risk management [J]". Market Modernization, no. 10, (2005), pp. 5-6.

[12] C Xiaohong, L Zhengjun. "Modern enterprise risk management and management audit [J]". China Economist, no. 6, (2006), pp. 168-170.

[13] G Jikun. "Modern enterprise comprehensive risk management system research [J]". Market Forum, no. 2, (2006), pp. 192-193.

[14] The Economist Intelligence Unit[EB / OL], no. 12, (1998).

[15] M Matt, "Risk Assessment As a Fraud Deterrent[J]", Hoosier Banker, no. 10, (2005), 12.

[16] E I Altman, "Financial Rations", Discriminated Analysis and the Prediction of Corporate Bankruptcy[J], Journal of Finance, vol. 9, no. 34, (1968).

[17] E 1Altrnan, "Manage credit risk: the new challenge in one thousand, the system comparison of economic and social [J]", vol. 4, (2003), pp. 90-94.

[18] H Elsinger, "Risk Assessment for Banking Systems[EB / OL]".

[19] H Elsinger, A Lehar, "Using Market Information for Banking System Risk Assessment[EB / OL]"

[20] COSO internal Control: Integrated Framework[EB / OL]

[21] L Guojing, Z Lei, "The commercial bank loan project risk assessment based on the risk matrix [J]", The Study of Finance and Economics, vol. 2, (2004), pp. 34-41.

[22] C Yi, "Enterprise dynamic risk management [EB/OL]".

[23] G Jianming, Y Jianan. "Technology risk assessment study [J]", Science \& Technology Progress and Policy, vol. 2, ,(2001), pp. 129-131.

[24] F Shaochuan, Z Wenjie, M Jun, "Research of risk analysis and the qualitative methods of electronic commerce [J]", Journal of Information, vol. 11,(2005), pp. 17-20.

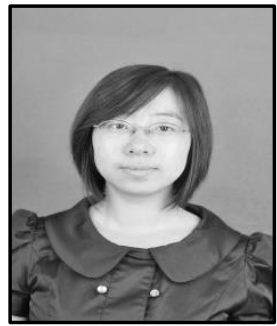

Authors

Jiamin Fang. She received her M.Sc. in Accounting (2008) from University. Now she is associate professor of accounting in Jilin Business and Technology College, Changchun China. Since 2012 she is section chief of College. Her current research interests include different aspects of Costs Accounting, Regional Economics, Industry Clusters and Accounting Theory and Practice. 